\title{
Spatial Analysis of Childhood Tuberculosis and Social Determinants in Bandar Lampung
}

\author{
Dyah Wulan Sumekar Rengganis Wardani ${ }^{1 *}$, Endro Prasetyo Wahono ${ }^{2}$ \\ ${ }^{1}$ Department of Public Health, Faculty of Medicine, University of Lampung, 35145 Bandar Lampung, \\ Indonesia \\ ${ }^{2}$ Department of Civil Engineering, Faculty of Engineering, University of Lampung, 35145 Bandar \\ Lampung, Indonesia
}

\begin{abstract}
Childhood tuberculosis is an overlooked aspect of the current tuberculosis epidemics; even the incidence is increasing and may influence children's growth and development. Several researches have studied social determinants as TB risk factors, but only a few researches have studied spatial analysis of childhood tuberculosis and social determinants. This research aimed to study spatial analysis of childhood TB and social determinants in Bandar Lampung, Indonesia. This research was cross sectional study which involved five community health centers that have childhood TB cases. Population of this research was all childhood tuberculosis cases in the study site. Sample of this research was 73 cases. Variables of this research were samples' residence geographical coordinates and social determinants (population density and proportion of poor family) of the related sub districts. Data was collected through CHSs' and sub districts' secondary data which then analyzed using overlay spatial analysis. The results showed that childhood TB tend to group in middle to high population density and middle proportion of poor families areas. Therefore, regarding in reducing childhood TB incidence, TB control programs should elaborate social determinants actions in areas with low social determinants.
\end{abstract}

Keywords. Childhood tuberculosis, spatial analysis, social determinants.

\section{Introduction}

Impact of tuberculosis (TB) as a global emergency has been established by World Health Organization (WHO) since 1993. But in general, the disease is only evaluated in adult population. Childhood TB has become an overlooked aspect of the current TB epidemic. According to WHO, an estimated 1.12 million children suffer from TB and 205,000 children died of TB in 2018. The morbidity and mortality number increased about twice and four times respectively, compared to the number in 2013 [1, 2]. However, the actual

* Corresponding author: dyah.wulan@fk.unila.ac.id 
burden of childhood TB is likely to be higher since the challenges in diagnosing TB in children which is quite difficult [3].

In Indonesia the proportion of childhood TB cases of all TB cases in 2018 was $10.69 \%$ (54,340 children of 511,873 cases). The number also increased ten times compared to 2011 which was only $0.72 \%[4,5]$.

In TB burden countries, children can get TB at any age but most commonly between 1-4 years. High risk of infection will occur once children unprotected, as well as of acceleration to TB once children infected. Previous research proved that if there were household contacts, on average $35 \%$ of child aged of five years or under will become infected, and ten percent of them will develop TB. Furthermore, children with TB will be disrupted in their growth and development $[6,7]$.

Review and researches stated that the incidence of TB as well as childhood TB, is influenced by social determinants, which directly or through TB risk factors affect TB [8]. Social determinants are terminology that refers to education, employment, income, race and social class that cause stratification or discrimination in community [9]. The stratification of social determinants also causes TB clusters, since TB patients who mostly have low social determinants tend to live in groups with people who also have low social determinants, which then will increase the risk for TB infection [10-12]. In the other hand, only few research studied spatial analysis of TB and social determinants, especially childhood TB.

This research aimed to study spatial analysis of childhood TB and social determinants in Bandar Lampung, Indonesia. Refer to Lampung Province Health Office; Bandar Lampung is city with high childhood TB cases in Lampung Province that was 359 childhood TB cases in 2018. Moreover, Bandar Lampung also a city with low social determinants [13].

\section{Methods}

A cross sectional study was used in this research and conducted in five Community Health Centre (CHC) in Bandar Lampung that recorded childhood TB patients, namely Kedaton, Way Halim, Gedong Air, Simpur and Way Kandis. Population of this research are all childhood TB patients registered at the concerned CHCs during October 2018 - February 2019. Sample of this research was the whole population who recorded with an accurate address, which were as 73 childhood TB patients.

Residence's geographical coordinates as well as social determinants of the childhood TB patients were decided as the variables in this research. Geographical Positioning System (GPS) device was used to collect geographical coordinate through ground check record. Meanwhile, social determinants represented by population density and proportion of poor family at sub-district level based on information from sub-district office. Population density in this research is the total population of the sub-district divided by its area in kilometers square. The density was grouped into three categories: (low density: $<2500$ persons/ $\mathrm{km}^{2}$; middle density: $2501-7500$ persons $/ \mathrm{km}^{2}$ and high density: $>7501$ persons/ $\mathrm{km}^{2}$ [14] . Furthermore, proportion of poor family is percentage of poor family in the sub districts, categorizing into: low $<5 \%$, middle $5,1 \%-10 \%$ and high $>10 \%$ [15].

Data obtained was then analyzed using overlay spatial analysis between geographical and social determinants point of views. Geographical Information System (GIS) software was used to visualize the results.

This research was ethically approved by Faculty of Medicine, University of Lampung. Moreover, respondents involved in this research also based on their voluntary basis. 


\section{Results}

It was clearly showed that there were eight $(40 \%)$ sub-districts with high population density, eleven or equivalent to $55 \%$ of sub-districts with middle population density and only one or equivalent to $5 \%$ sub-district categorized as a low population density. Moreover, there was only $5 \%$ of sub-district which was considered as a high proportion of poor family, and the rest of $50 \%$ and $45 \%$ of concerned sub districts were categorized as middle proportion and low proportion of poor family respectively.

This research proved that childhood TB patients tend to be clustered in the sub-district of Tanjung Karang Pusat, Kedaton and Rajabasa. Tanjung Karang Pusat and Kedaton subdistricts had high population density; meanwhile Rajabasa sub-district considered as middle population density. Result of overlay analysis of childhood TB patients' residence coordinates and sub districts' population density was presented in figure 1 .

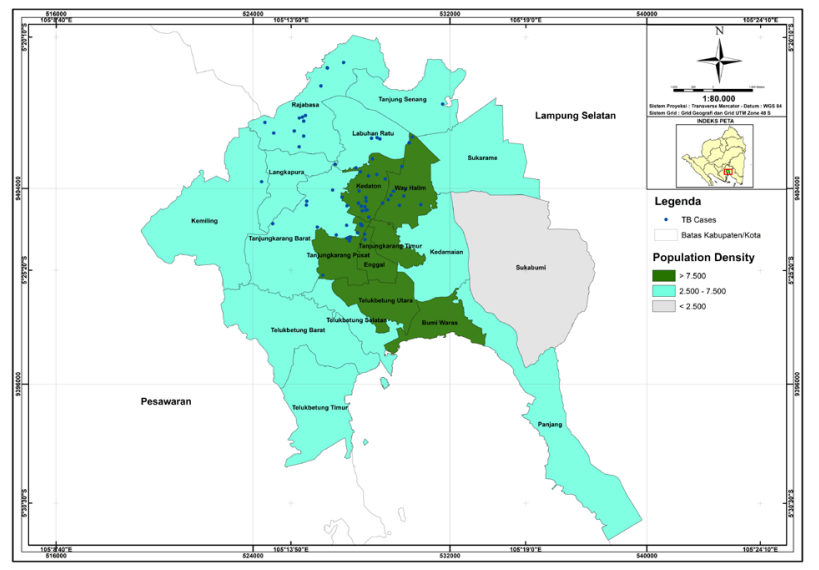

Fig.1. Overlaid Childhood TB Patients' Residences and Population Density

According to proportion of poor family, this research also evidenced that both Tanjung Karang Pusat and Kedaton sub-districts had middle proportion of poor family meanwhile Rajabasa sub-district categorized as low proportion of poor family. Result of the overlay analysis of childhood TB patients' residence coordinates and sub districts' proportion of poor family was presented in figure 2 .

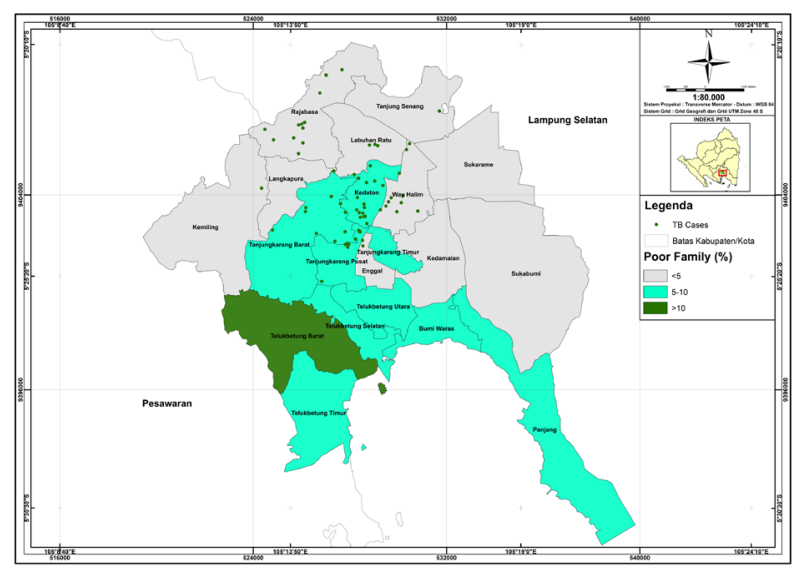


Fig. 2. Overlaid Childhood TB Patients' Residences and Proportion of Poor Family

\section{Discussions}

This research proved that childhood TB cases period October 2018 - February 2019 in Bandar Lampung are not evenly distributed, but the most cases occurred in highly populated areas with population density higher than 7501 persons $/ \mathrm{km}^{2}$. These results are consistent with research conducted in Lingyi, China, which showed that distribution of TB patients mostly occurred in high population density areas [16]. However, the results of this research differ from studies conducted in Hong Kong which showed that the distribution of TB patients did not only occur in area with high population density [17]. The inconsistency is mainly due to the facts that Hong Kong is a city with a very dense population; therefore its population density is not too different from one region to another. A review of several research results stated that living in a high-density population area is one of the risk factors for TB, since it is closely related to TB transmission. Furthermore, common knowledge proved that living in high population density area is closely related to a low category of social determinants. On the other hand, social determinants, which include education, employment, income and social class, are also well known as TB risk factors [18, 19].

This paper showed that in October 2018 - February 2019 there were three spatial groups of childhood TB cases. The results of this analysis are consistent with research conducted in Bandar Lampung, which obtained two significant clusters in TB patients in 2012 as well as three significant clusters in 2013 - 2015 [10, 20].

In this study, the tendency of spatial grouping, childhood TB cases, was occurred in Tanjung Karang Timur, Kedaton and Rajabasa sub-districts. Tanjung Karang Timur and Kedaton sub-districts are sub-districts with a high population density as well as a middle proportion of the poor population. Meanwhile, Rajabasa sub-district is considered as a subdistrict with a middle population density as well as a low proportion of the poor population. Referring to the results, tendency of spatial cluster regarding childhood TB cases has been confirmed. Even the three spatial clusters were located separately, they are categorised into similar low social determinants characteristics, indicating by their high population density or their proportion and moderate of poor family. The results of this study are consistent with research conducted in Vittoria, Brazil, which shows that TB clustering occurs in areas with a low Urban Quality of Life Index. The index is acquired from a combination of four main indicators namely: education, environment, housing conditions and income [21]. The results presenting in this paper are also consistent with research conducted in Portugal, founding that TB clustering tends to be occurred in densely populated areas [22]. This research is also consistent with a study conducted in Hermosillo, Mexico, which found that TB clustering tends to be occurred in areas with a high deprivation index. Deprivation index is measured based on the following indicators: education, income, housing conditions, density and vehicle availability [23]. Tuberculosis is a disease that has a tendency to be correlated with spatial and geographical location of the patients. The tendency can be described by facts that TB patients, who mostly living with a low social determinants, tends to live in a community that not only categorizing as having a low social determinants, but also having a higher risk for TB infection. The variety of social determinant of the communities will also led to differences both number and location of the TB cases, this phenomenon will tends to form a TB cluster [24].

The results also proved that the tendency of spatial grouping occurred in a relatively narrow radius with corresponding location where the most cases was located in each group. Research also shows that a narrow clustering radius is an indication that there is a process of transmission from one patient to another since there is a high likelihood occurrence of physical contacts. Research conducted in Dallas, USA, found that TB patients with nearby 
locations had the same strains of bacteria, which indicated that local transmission occurred [25]. Since the cluster radius found in this study is relatively large, it will be necessary to discuss further on what will be the possible mechanism of TB transmission in a spatial cluster of childhood TB in Bandar Lampung.

\section{Conclusion}

In this paper, it can be concluded that childhood TB in Bandar Lampung is not randomly distributed but tends to occur in areas with low social determinants, which are areas with high population density as well as high proportion of poor family. Therefore, regarding to the effort of reducing childhood TB incidence, TB control programs should also elaborate with social determinants intervention especially in the low social determinants areas.

\section{References}

1. World Health Organization. Global Tuberculosis Report 2019. (Geneva, WHO, 2019).

2. World Health Organization. Global Tuberculosis Report 2014. (Geneva, WHO, 2014).

3. Dodd PJ, Gardiner E, Coghlan R, Seddon JA. Burden of childhood tuberculosis in 22 high-burden countries: a mathematical modelling study. Lancet Glob. Heal. 2(8):e453-e459 (2012).

4. Republic of Indonesia Ministry of Health. Indonesia Health Profile 2018.(Jakarta, Kemenkes, 2019).

5. Republic of Indonesia Ministry of Health. Indonesia Health Profile 2013.(Jakarta, Kemenkes, 2014).

6. Fox GJ, Barry SE, Britton WJ, Marks GB. Contact investigation for tuberculosis: a systematic review and meta-analysis. Eur. Respir. J. 41:140-56 (2013).

7. Bonnet M, Kyakwera C, Kyomugasho N, Atwine D, Mugabe F, Nansumba M. Prospective cohort study of the feasibility and yield of household child tuberculosis contact screening in Uganda. Int. J. Tuberc. Lung Dis. 21(8):862-8 (2017).

8. Lönnroth K, Jaramillo E, Williams BG, Dye C, Raviglione MC. Drivers of Tuberculosis Epidemics: The Role of Risk Factors and Social Determinants. Soc. Sci. Med. 68:2240-6 (2009).

9. Solar O, Irwin A. A Conceptual Framework for Action on the Social Determinants of Health. Social Determinants of Health Discussion Paper 2 (Policy and Practice). (Geneva, WHO, 2010).

10. Wardani D, Wahono E. Spatio-Temporal Dynamics of Tuberculosis Clusters in Indonesia. Indian J. Community Med. 45(1):43-7 (2020).

11. Wardani D, Wahono E. Prediction Model of Tuberculosis Transmission Based on Its Risk Factors and Socioeconomic Position in Indonesia. Indian J. Community Med. 43(3):204-8 (2018).

12. Wardani D, Wahono E. Predominant Determinants of Delayed Tuberculosis Sputum Conversion in Indonesia. Indian J. Community Med. 44(1):53-7 (2019).

13. Central Bureau of Statistics. Number of Poor People by Province 2007 - 2017. (Jakarta, BPS, 2017).

14. Central Bureau of Statistics. Development of Several Key Indicators. (Jakarta, BPS, 2011). 
15. United Nation Development Program. Human Poverty Index 2012 [Internet]. 2012. Available from: http://hdr.undp.org.

16. Wang T, Xue F, Chen Y, Ma Y, Liu Y. The Spatial Epidemiology of Tuberculosis in Linyi. BMC Public Health. 12(885) (2012).

17. Chan-yeung M, Yeh AGO, Tam CM, Kam KM, Leung CC, Yew WW, et al. SocioDemographic and Geographic Indicators and Distribution of Tuberculosis in Hong Kong: A Spatial Analysis. Int. J. Tuberc. Lung Dis. 9(12):1320-6 (2005).

18. Lönnroth K, Castro KG, Chakaya JM, Chauhan LS, Floyd K, Glaziou P, et al. Tuberculosis Control and Elimination 2010 - 50: Cure, Care, and Social Development. Lancet. 375:1814-29 (2010).

19. Lönnroth K, Jaramillo E, Williams BG, Dye C, Raviglione M. Drivers of Tuberculosis Epidemics: The Role of Risk Factors and Social Determinants. Soc. Sci. Med. 68:2240-6 (2009).

20. Wardani D, Lazuardi L, Mahendradhata Y, Kusnanto H. Clustered Tuberculosis Incidence in Bandar Lampung, Indonesia. WHO South-East Asia J. Public Heal. 3(2) (2014).

21. Maciel E, Pan W, Dietze R, L PR, Vinhas S, Ribeiro F, et al. Spatial Patterns of Pulmonary Tuberculosis Incidence and Their Relationship to Socio-Economic Status in Vitoria, Brazil. Int. J. Tuberc. Lung Dis. 14(11):1395-402 (2010).

22. Couceiro L, Santana P, Nunes C. Pulmonary Tuberculosis and Risk Factors in Portugal: A Spatial Analysis. Int. J. Tuberc. Lung Dis. 15(11):1445-54 (2011).

23. Alvarez-Hernández G, Lara-Valencia F, Reyes-Castro P A, Rascón-Pacheco R A. An Analysis of Spatial and Socio-Economic Determinants of Tuberculosis in Hermosillo, Mexico, 2000-2006. Int. J. Tuberc. Lung Dis. 14(6):708-13 (2010).

24. Nunes C. Tuberculosis Incidence in Portugal: Spatiotemporal Clustering. Int. J. Health Geogr. 6(30) (2007).

25. Moonan PK, Bayona M, Quitugua TN, Oppong J, Dunbar D, Jost KC, et al. Using GIS Technology to Identify Areas of Tuberculosis Transmission and Incidence. Int. J. Health Geogr. 3(23) (2004). 